\title{
Cathodoluminescence and fluid inclusion analyses of mineral veins within major thrusts in the Shimanto accretionary complex: evidence of hydraulic fracturing during thrusting
}

\author{
Hideki Mukoyoshi ${ }^{1}$, Tetsuro Hirono ${ }^{2}$, Kotaro Sekine ${ }^{3}$, Noriyoshi Tsuchiya $^{4}$, and Wonn Soh ${ }^{5}$ \\ ${ }^{1}$ Marine Works Japan, Yokohama 236-0042, Japan \\ ${ }^{2}$ Department of Earth and Space Science, Graduate School of Science, Osaka University, Toyonaka 560-0043, Japan \\ ${ }^{3}$ Institute of Fluid Science, Tohoku University, Sendai 980-8577, Japan \\ ${ }^{4}$ Graduate School of Environmental Studies, Tohoku University, Sendai 980-8579, Japan \\ ${ }^{5}$ Kochi Institute for Core Sample Research, Japan Agency for Marine-Earth Science and Technology, Nankoku 783-8502, Japan
}

(Received January 11, 2007; Revised June 5, 2007; Accepted June 7, 2007; Online published August 31, 2007)

\begin{abstract}
To elucidate fluid-rock interaction in a seismogenic zone along a plate-subduction boundary, we investigated the occurrence of mineral veins within the major thrusts in the Shimanto accretionary complex and examined their microstructures using a cathodoluminescence technique. We found discriminative structures, for example, a jigsaw-puzzle structure, within the quartz veins in the thrusts, which could indicate that hydraulic fracturing occurred by abnormal pore-fluid pressure during thrusting. Pore pressure values, estimated quantitatively by fluid inclusion analyses, were 3-27 MPa higher than the surrounding parts, which may be direct evidence of abnormal pore-fluid pressure. High pore-fluid pressures and subsequent hydraulic fracturing may play an important role within major thrusts along a plate-subduction boundary.
\end{abstract}

Key words: Hydraulic fracturing, seismogenic zone, cathodoluminescence, Shimanto accretionary complex.

\section{Introduction}

Pore-fluid pressure is important in decreasing in situ effective stress. In environments with abundant, readily available fluids, fault zones can be expected to have high porefluid pressure. Many researchers have reported that fluid pressures can be much greater than hydrostatic pressures in an accretionary prism, where they can aid thrust faulting (e.g., Moore, 1989). Thus, fluid-rock interactions associated with fracture triggering by high pore-fluid pressure may play an important role in seismogenesis along a platesubduction boundary. However, the process is not well understood owing to the difficulty of directly observing the occurrence of fluid-rock interactions under situ conditions. Recent studies have shown that the Shimanto accretionary complex preserves an ancient plate-subduction boundary fault containing pseudotachylyte as evidence of coseismic slip (e.g., Ikesawa et al., 2003). An investigation of such an ancient seismogenic zone might be useful for understanding fluid-rock interaction in this setting.

Therefore, to elucidate the relationships and reactions between fluid flow and mineral precipitation in the seismogenic zone, we investigated the occurrence of syntectonic mineral veins in the Shimanto accretionary complex and examined their microstructure by using a cathodoluminescence $(\mathrm{CL})$ technique.

Copyright (c) The Society of Geomagnetism and Earth, Planetary and Space Sciences (SGEPSS); The Seismological Society of Japan; The Volcanological Society of Japan; The Geodetic Society of Japan; The Japanese Society for Planetary Sciences; TERRAPUB.

\section{Geological Setting}

\subsection{Mélange in the Shimanto accretionary complex}

The Shimanto accretionary complex on Shikoku Island, southwestern Japan, is divided into Cretaceous and Tertiary units (Taira et al., 1980). The Cretaceous unit includes several Mélanges, such as the Okitsu, Kure, Yokonami, and Mugi Mélanges (Fig. 1(a)). A specific thick pile of tectonic Mélange is considered a candidate for plate-boundary rock because it comprises fault-related, chaotic rocks, including exotic fragments and blocks of basalt and chert, and exhibits repeated piles formed by thrusts parallel or sub-parallel to the paleo-plate boundary (e.g., Kimura and Mukai, 1991). To understand the fluid-rock interactions within a plateboundary fault and other major thrust types, such as out-ofsequence thrust (OST), we investigated the late Cretaceous Mugi and Kure Mélanges and sampled mineral veins from within their representative fault zones.

\subsection{Mugi Mélange}

The Mugi Mélange occurs in thrust sheets (Fig. 1(b)) and is composed of a matrix of black scaly shales that enclose disrupted pillow basalts, pelagic to hemipelagic red shales, and sandstone lenses (Kumon, 1981). An upper roof thrust, the Minami-Awa Fault, bounds a coherent, sandstone-dominated unit of the Hiwasa Formation. Onishi and Kimura (1995) reported five repetitions of oceanic floor stratigraphies in the Mélange, revealing their origin as underthrusts in an accretionary prism.

The Minami-Awa Fault is approximately $1.5 \mathrm{~m}$ thick and is composed predominantly of cataclasite, which originated from sandstone with shale (Fig. 2(a)). The fault strikes E$\mathrm{W}$ and dips steeply northward. Composite planar fabrics 


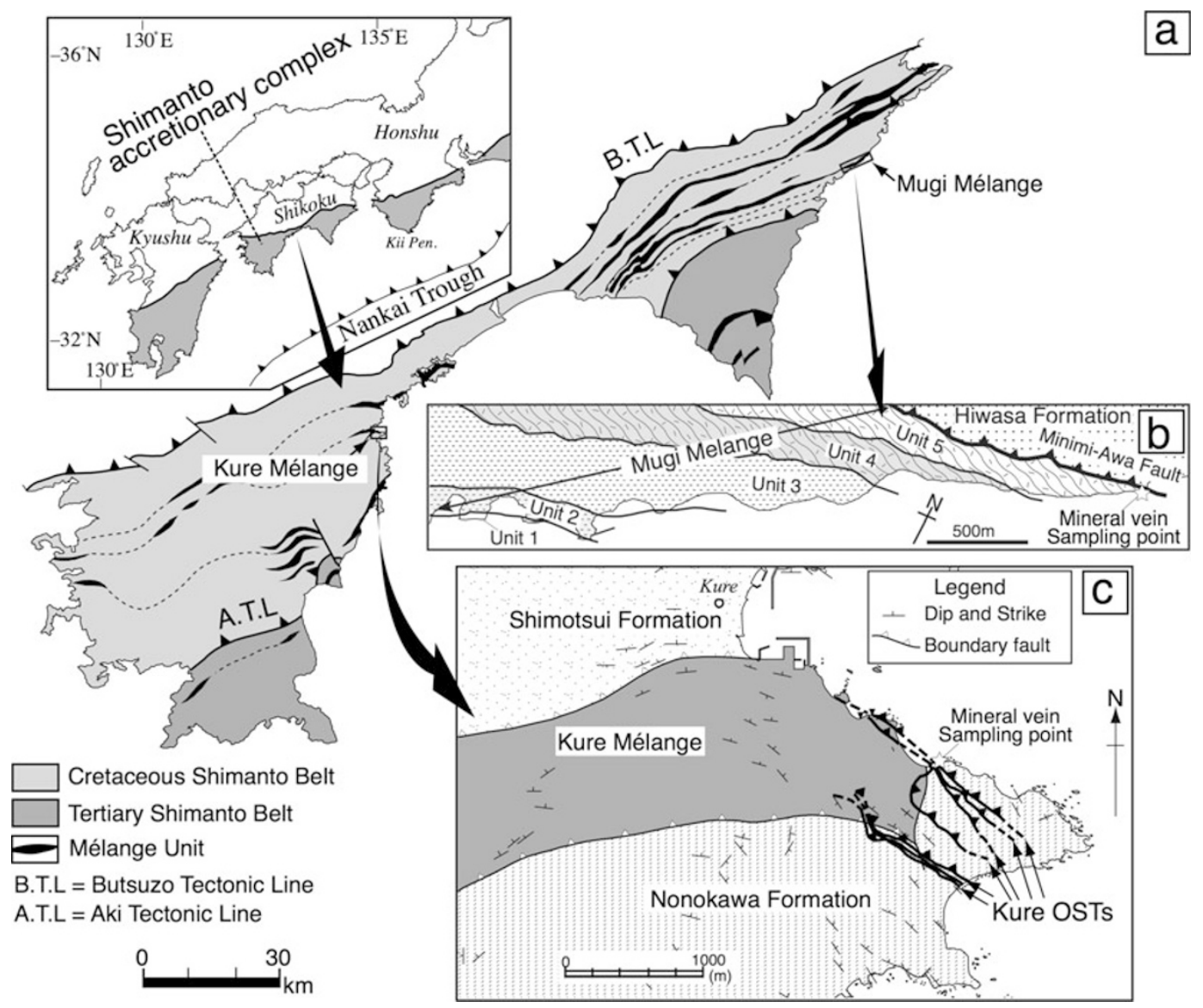

Fig. 1. (a) Location and geological map of the Shimanto accretionary complex, south Shikoku, Japan. (b) Geological map of the Mugi Mélange, modified from Kitamura et al. (2005). (c) Geological map of the Kure Mélange, modified from Mukoyoshi et al. (2006). OSTs, out-of-sequence thrusts.

are well developed within the fault, and the asymmetric fabrics and striation lineations on the fault surface indicate that the fault is a reverse fault with a component of sinistral shear (Kitamura et al., 2005). Numerous quartz, laumontite, and calcite veins are recognized within the linear Y-plane, and fragmented sandstone blocks are found along the P-plane. Some dilatant jog-filled veins are also recognized in the fault zones. Ikesawa et al. (2005) reported that the fault experienced a temperature of approximately 170$190^{\circ} \mathrm{C}$ and that it does not exhibit any thermal discontinuity with the upper Hiwasa Formation. Kitamura et al. (2005) found pseudotachylyte in the fault, and suggested that the fault corresponded to a seismogenic roof decollement.

\subsection{Kure Mélange}

The Kure Mélange is interleaved within a coherent Late Cretaceous sedimentary sequence, the Shimotsui and Nonokawa Formations (Fig. 1(c)). The Kure Mélange consists of boudinaged blocks of pillow basalts, cherts, variously colored shales, and sandstone fragments embedded in a black shale matrix. An en-echelon fault system cuts across the Kure Mélange and Nonokawa Formation, and a paleogeothermal discontinuity of $80^{\circ} \mathrm{C}$ occurs within the fault system. Mukoyoshi et al. (2006) inferred that the faults of the en-echelon fault system correspond to branched subOSTs at depths of $2.5-5.5 \mathrm{~km}$ and also reported the occurrence of pseudotachylyte within the OSTs.
Figure 2(b) shows one of the sub-OSTs in the Kure Mélange. This fault zone is composed of fault breccia, fault gouge, and cataclasite, is approximately $500 \mathrm{~mm}$ thick, and contains a major slip zone that is $0.5-10 \mathrm{~mm}$ thick. The cataclasite is composed of sub-angular to rounded fragments of the host rocks (sandstone, black shale, and greenish shale) and fragmented mineral veins (quartz and calcite). The fault zone has Y-P-R composite planar fabrics that indicate a dip slip of the fault. Quartz and calcite veins are well developed within the fragmented sandstone blocks along the Pplane and within the major slip zone. The veins which filled major slip zone are linear and parallel to the shear surface. Diletant jog-filled veins are not recognized around the fault zones.

\section{Methods}

We collected P-plane-formed, fragmented sandstone blocks with filled vein from the Minami-Awa Fault in the Mugi Mélange (Fig. 2(a)) and main shear surface from along the OSTs in the Kure Mélange (Fig. 2(b)). To determine their microstructural observation, we used not only an optical microscope but also a scanning electron microscopy-cathodoluminescence (SEM-CL) technique. We also conducted fluid inclusion analyses to investigate the temperature and pressure conditions during the precipitation and deformation. These methods are described in detail below. 

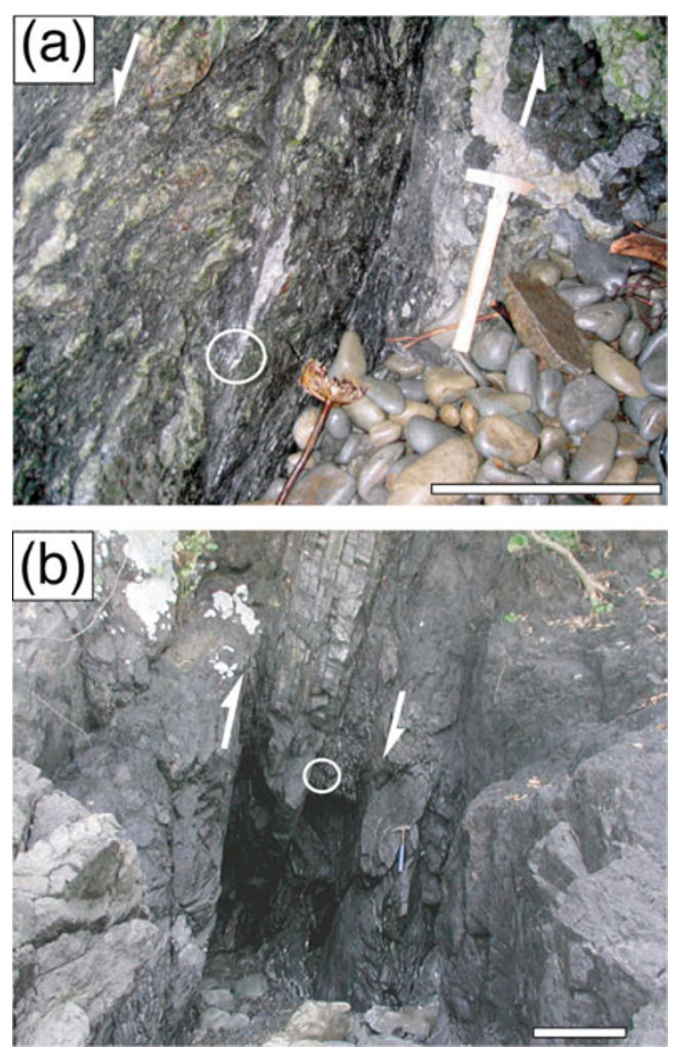

Fig. 2. (a) Photograph of a portion of the Minami-Awa Fault. (b) Photograph of a portion of an OST in the Kure Mélange. Each scale bar is 30 $\mathrm{cm}$. White circle indicate sampling point of vein.

\subsection{The scanning electron microscopy-cathodo-} luminescence (SEM-CL) technique

Cathodoluminescence (CL) is luminescence from crystals induced by electron bombardment. Because of a lack of stoichiometry, structural imperfections, or impurities in a mineral can cause variations in CL wavelength and intensity, CL enables visualization of mineral microstructures that formed in response to growth zonation, microfracturing, dissolution, deformation, and recrystallization. We used CL observation aided by SEM to examine the quartz vein samples.

We prepared $100-\mu \mathrm{m}$-thick doubly polished sections for CL analysis and examined the sections under a transmitted light optical microscope for mineral assemblages in the veins. We subsequently coated the sections with carbon for CL analysis and adjusted the voltage and sample current for electron stimulation to $20-25 \mathrm{keV}$ and 5-15 nA, respectively, to obtain optimal contrast in luminosity. To obtain CL digital images, we used a panchromatic CL detector (Mini-CL, Oxford Instruments) with a slow electron beam scanning with a Hitachi S2460N SEM.

\subsection{Fluid inclusion analysis}

We conducted microthermometry on primary fluid inclusions in veins by using a Linkam THMS 600 heatingcooling stage. Water-rich and methane-rich inclusions were identified by laser Raman spectroscopy. The coexistence of water-rich and methane-rich inclusions suggests that the water was saturated with methane when the vein formed (Mullis, 1979). We performed a heating experiment on the water-rich inclusions and a cooling experiment on the methane-rich inclusions. Methane bubbles appeared below $-83^{\circ} \mathrm{C}$ in the samples. No solid carbon dioxide was observed during the experiment, suggesting that the amount of carbon dioxide was very small (Burruss, 1981) and that the effect of carbon dioxide on the homogenization temperature of the methane-rich inclusions was negligible. The melting temperature of the methane-rich inclusions could not be analyzed owing to their small size. The homogenization temperature of the water-rich inclusions provides a direct estimation of the trapping temperature because it coincides with the temperature of methane saturation of the water when the fluid was trapped. We obtained methane density from the homogenization temperature in the cooling experiment. The mean value of the homogenization temperature in the heating experiments was taken as the trapping temperature, and the cooling experiment result was taken to indicate the trapping condition. An isochore line was chosen from the basic data of Saxena and Fei (1987) for methane-rich fluid with the computer program of Brown (1989). We then determined the trapping temperature from the mean value of the homogenization temperatures and also calculated the fluid pressure from the isochore line in the pressure-temperature space by combining the trapping temperature.

\section{Microstructures of Mineral Veins \\ 4.1 Jigsaw-puzzle structure within veins}

Figure 3(a) shows an optical microscope image of the anastomosing network of quartz veins in the sandstone blocks along the P-plane (Fig. 2(a)). The sandstone blocks are extremely disrupted by the veins. Figure 3(b) shows an SEM-CL image of a representative portion of a vein. The grayscale contrast resulted from slight differences in chemical composition, which might be related to different stages of precipitation. We recognized the original host rock and two precipitation stages: host sandstone blocks (SS) with a fragmented structure, anastomosing portions (CLgray quartz), and thin cracks (CL-bright quartz). The irregular SS pattern, identified as a jigsaw-puzzle structure, is considered not to have resulted from shearing but to indicate that the crystals (CL-gray quartz) were apparently floating freely as they grew.

\subsection{Multiple precipitation histories within an appar- ently single crystal}

Four or five idiomorphic blocky-elongate quartz crystals $0.5-5 \mathrm{~mm}$ in size were recognized in the quartz vein within the Kure Mélange OST (Fig. 4(a)). Shear textures such as composite planar fabrics were not observed within the vein. The SEM-CL image showed that the vein has a complex precipitation-deformation history. An apparent single crystal seen under the optical microscope was revealed in the SEM-CL image to comprise several subcrystals (Figs. 4(b) and (e)). We recognized four precipitation stages: CL-black quartz, CL-light gray quartz, CL-gray quartz, and CL-bright quartz (Fig. 4(b)). The CL-black and CL-light gray portions are primary euhedral crystals with zoning at the crystal edge that consists of alternating bands of CL-black and -light gray. The CL-gray behaves as a matrix of the crystals. CL-black and light gray crystals were injected, fractured, 

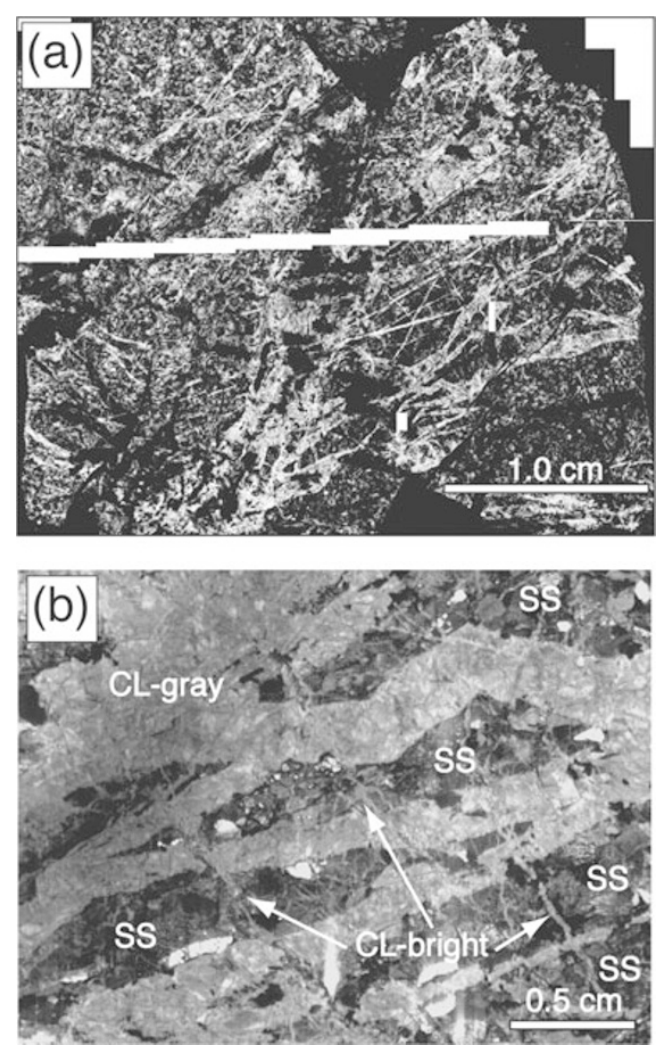

Fig. 3. (a) Optical microscope image of a quartz-calcite-filled vein within the Minami-Awa Fault. (b) Scanning electron microscopy-cathodoluminescence (SEM-CL) image of a quartz vein in the Minami-Awa Fault. SS, sandstone blocks.

floated, and sealed by the CL-gray quartz at a late stage (Figs. 4(c) and (d)). The directions of fractures within the vein are random. These characteristics suggest hydraulic fracturing resulting from high pore-fluid pressure. The CLbright quartz is thought to have filled open spaces in CLblack and CL-gray at the latest stage. The distributions of each sub-crystal are summarized in Fig. 4(e).

\subsection{Pressure-temperature variation within veins}

Fluid-inclusion data at 11 points within the quartz vein shown in Fig. 4(b) are presented in Fig. 5(a). Figure 5(b) shows the cumulative data of measured homogenization temperatures at all 11 points. The homogenization temperatures of the water-rich inclusions in CL-black and CL-light gray ranged from 125 to $200^{\circ} \mathrm{C}$ (average: $165^{\circ} \mathrm{C}$ ) and were lower than the temperatures of those in CL-gray (range: $140-240^{\circ} \mathrm{C}$; average: $181^{\circ} \mathrm{C}$ ). The homogenization temperatures of the methane-rich inclusions do not show much of a difference between CL-black and CL-light gray (range: -102 to $-85^{\circ} \mathrm{C}$; average: $-90.6^{\circ} \mathrm{C}$ ) and $\mathrm{CL}$-gray (range: -102 to $-85^{\circ} \mathrm{C}$; average: $-91.3^{\circ} \mathrm{C}$ ). At locations $1,2,4$, $6,7,8$, and 11 , the pressure and temperature condition (PT) of CL-gray was higher (102-142 MPa) than that of CLblack and CL-light gray (99-115 MPa) (Fig. 5(c)). Only point 1 shows especially high pressure values of 124-142 $\mathrm{MPa}$; other values crowd around 100-120 MPa. Although the pressure values of CL-gray decrease and range from 102 to $121 \mathrm{MPa}$, if we avoid the value of point 1 , the pressure values of CL-gray are slightly higher than those of CL-black and CL-light gray.

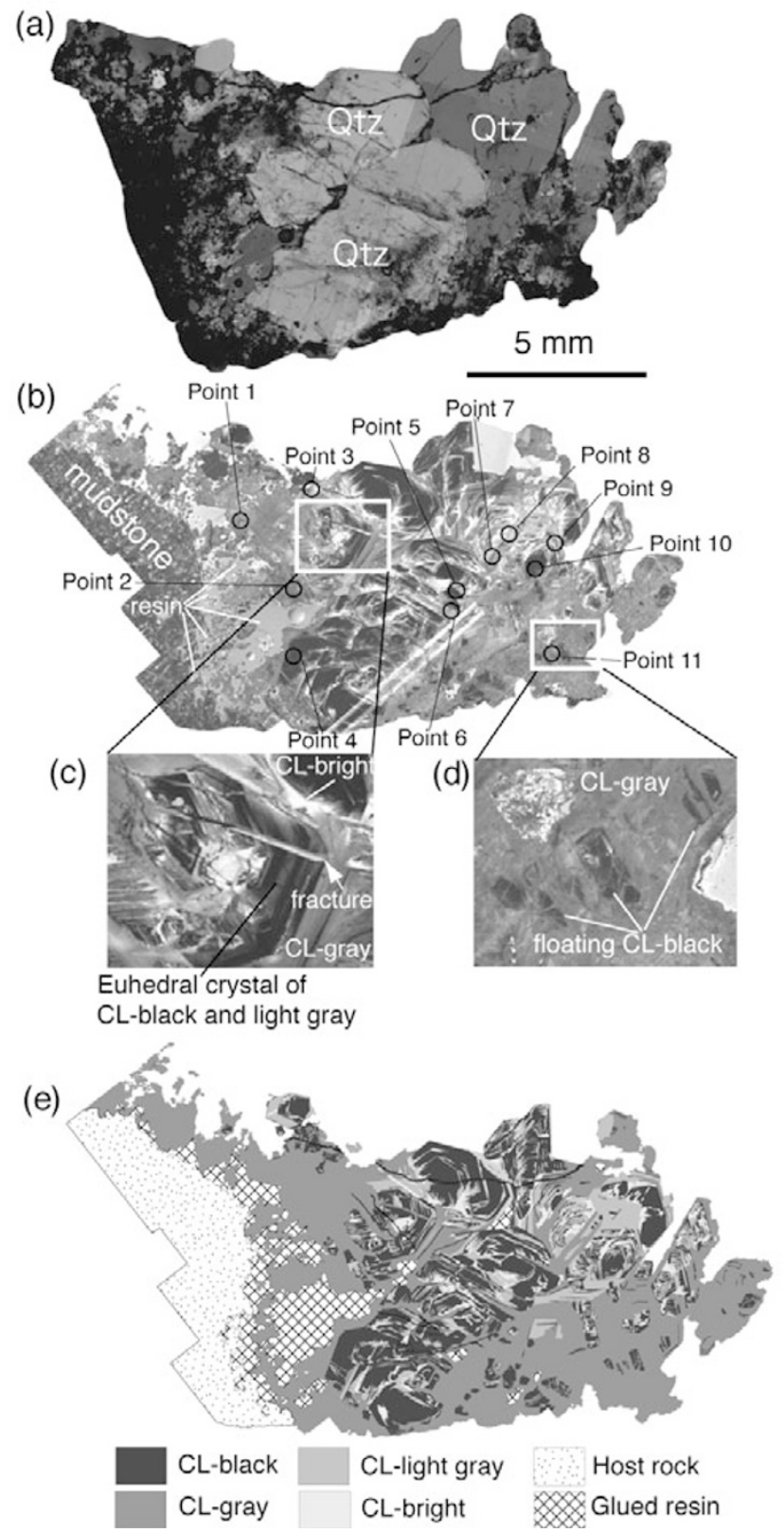

Fig. 4. Complex precipitation history of a quartz vein within the Kure Mélange OST. (a) Optical microscope image. (b) SEM-CL image. (c) High-magnification SEL-CL image of fractured primary euhedral CL-black and light gray quartz. (d) High-magnification SEL-CL image of floating structure. (e) Sketch of SEM-CL image.

\section{Hydraulic Fracturing along a Major Thrust Fault}

The observed irregular CL-gray pattern of quartz-filled veins within the Minami-Awa Fault, identified as a jigsawpuzzle structure, is considered to be strong evidence for hydraulic fracturing because high pore-fluid pressure is a requirement for the crystals to float freely. The texture, which indicates that the primary euhedral CL-black and CLlight gray quartz crystals were injected, fractured, floated, and then sealed by the late-stage CL-gray quartz within the vein in the Kure Mélange OST (Figs. 4(c) and (d)), also suggests hydraulic fracturing.

The occurrence of hydraulic fracturing implies that abnormal pore-fluid pressure was generated, breaking up both 

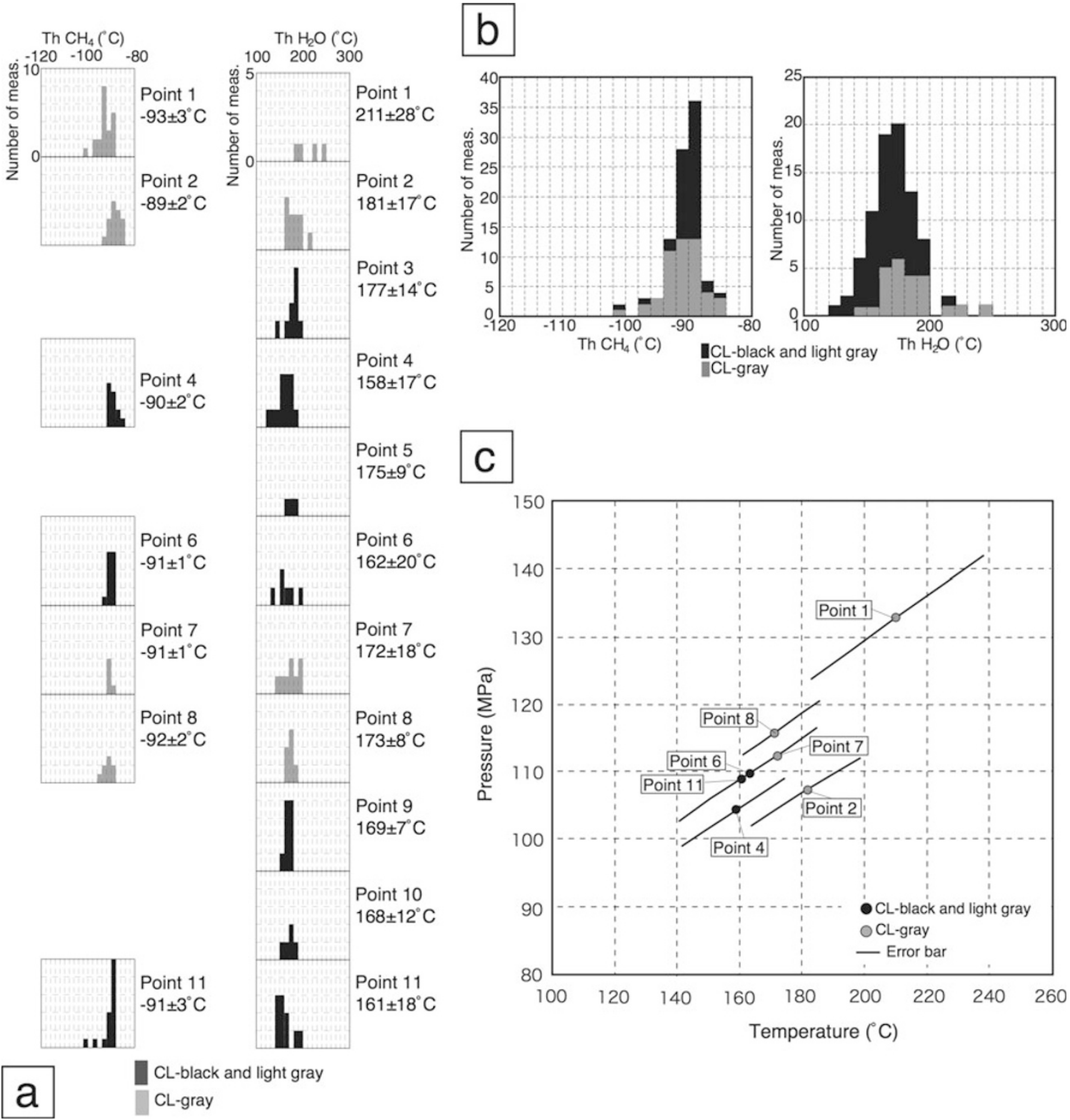

Fig. 5. (a) Histograms of homogenization temperatures of each point shown in Fig. 4(b). (b) Cumulative measured homogenization temperatures for all points. (c) Isochore data showing pressure-temperature conditions at points 1, 2, 4, 6, 7, 8, and 11. Error bars were calculated from mean methane density and temperature errors.

the original host rock and previously precipitated mineral veins. Pore pressure values in the CL-black, CL-gray, and CL-light gray quartz in the Kure Mélange OST were quantitatively estimated by fluid-inclusion analyses, and the values in the CL-gray quartz were estimated to be a maximum of $27 \mathrm{MPa}$ higher than those in the CL-black and CL-light gray quartz. This pressure differential may be direct evidence of high pore-fluid pressure. Unfortunately, the lithostatic pressure during the fracturing is not known, although it should be lower than the pore pressure in the CL-gray quartz.

Both the Minami-Awa Fault in the Mugi Mélange and the Kure Mélange OSTs are reported to contain pseudotachylytes and are considered to be seismogenic faults in and around a plate-subduction boundary (Kitamura et al., 2005; Mukoyoshi et al., 2006). Although in this study the obvious relationship between mineral precipitation and hy- draulic fracturing and seismic faulting with frictional heating was not resolved, the high pore-fluid pressure may have functioned as a faulting trigger and, therefore, may have played an important seismogenic role along a platesubduction boundary.

\section{Conclusions}

Although mineral veins and their P-T condition in the Shimanto accretionary complex have been well studied (e.g., Sakaguchi, 1996), we report here the first direct evidence of hydraulic fracturing in this complex. Our cathodoluminescence analyses revealed that there are complicated microstructures within the mineral veins in the major thrusts that cannot be observed under an optical microscope. The occurrence of abnormal pore-fluid pressure was revealed by detailed analyses of the fluid inclusions within the veins. Further systematic study combining cathodoluminescence 
observation with fluid inclusion measurement can contribute to a better understanding of fluid-rock interaction in and around major thrust faults in accretionary prisms.

Acknowledgments. We are grateful to Nobuo Hirano and Taketo Kikuchi for their technical support in the operation of SEM-CL. We thank Vincent Famin and Yoshitaka Hashimoto for their constructive reviews, and we also thank Editor Akira Takada for editing this paper. This research was supported by the Ministry of Education, Science, Sports and Culture, Grant-in-Aid for Young Scientists 18740323, 2006.

\section{References}

Brown, P. E., FLINCORE: A microcomputer program for the reduction and investigation of fluid-inclusion data, Am. Mineral., 74, 1390-1393, 1989.

Burruss, R. C., Analysis of phase equilibria in C-O-H-S fluid inclusions: Mineral Association of Canada Short Course Handbook, 6, 138-156, 1981.

Ikesawa, E., A. Sakaguchi, and G. Kimura, Pseudotachylyte from an ancient accretionary complex: Evidence for melt generation during seismic slip along a master decollement?, Geology, 31, 637-640, 2003.

Ikesawa, E., G. Kimura, K. Sato, K. Ikehara-Ohmori, Y. Kitamura, A. Yamaguchi, K. Ujiie, and Y. Hashimoto, Tectonic incorporation of the upper part of oceanic crust to overriding plate of a convergent margin: An example from the Cretaceous-early Tertiary Mugi Mélange, the Shimanto Belt, Japan, Tectonophysics, 401, 217-230, 2005.

Kimura, G. and A. Mukai, Underplated units in an accretionary complex: Melange of the Shimanto Belt of eastern Shikoku, southwest Japan, Tectonics, 10, 31-50, 1991.

Kitamura, Y., K. Sato, E. Ikesawa, K. Ohmori-Ikehara, G. Kimura,
H. Kondo, K. Ujiie, C. T. Onishi, K. Kawabata, Y. Hashimoto, H. Mukoyoshi, and H. Masago, Melange and its seismogenic roof decollement: A plate boundary fault rock in the subduction zoneAn example from the Shimanto Belt, Japan, Tectonics, 24, TC5012, doi:10.1029/2004TC001635, 2005.

Kumon, F., Shimanto Supergroup in the southern part of Tokushima Prefecture, Southwest Japan, J. Geol. Soc. Jpn., 87, 277-295, 1981.

Moore, J. C., Tectonics and hydrogeology of accretionary prisms: role of the decollement zone, J. Struct. Geol., 11, 95-106, 1989.

Mukoyoshi, H., A. Sakaguchi, K. Otsuki, T. Hirono, and W. Soh, Coseismic frictional melting along an out-of-sequence thrust in the Shimanto accretionary complex: Implications on the tsunamigenic potential of splay faults in modern subduction zones, Earth Planet. Sci. Lett., 245, 330-343, 2006.

Mullis, J., The system methane-water as a geologic thermometer and barometer from the external part of the central Alps, Bull.Mineral., 102, 526-536, 1979.

Onishi, C. T. and G. Kimura, Change in fabric of melange in the Shimanto Belt, Japan: Change in relative convergence?, Tectonics, 14, 1273-1289, 1995.

Sakaguchi, A., High paleogeothermal gradient with ridge subduction beneath the Cretaceous Shimanto accretionary prism, Southwest Japan, Geology, 24, 795-798, 1996.

Saxena, S. K. and Y. Fei, Fluids at crustal pressure and temperatures, I: pure species, Contrib. Mineral. Petrol., 95, 370-375, 1987.

Taira, A., M. Tashiro, M. Okamura, and J. Katto, The geology of the Shimanto Belt in Kochi Prefecture, Shikoku, Japan, in Geology and Paleontology of the Shimanto Belt, edited by A. Taira and M. Tashiro, Rinyakosaikai Press, Kochi, 319-389, 1980.

H. Mukoyoshi (e-mail: mejika988@yahoo.co.jp), T. Hirono, K. Sekine, N. Tsuchiya, and W. Soh 